\title{
Phase relations between climate proxy records: Potential effect of seasonal precipitation changes
}

\author{
Hezi Gildor ${ }^{1}$ \\ Department of Environmental Sciences, Weizmann Institute of Science, Israel \\ Michael Ghil \\ Department of Atmospheric Sciences and Institute of Geophysics and Planetary Physics, UCLA
}

\begin{abstract}
.
Phase relations between climate variables are critical in order to ascertain the main mechanisms driving glaciation cycles. Proxy records from ice cores are commonly assumed to represent annual mean averages. These averages, however, may be biased toward a particular season due, for example, to a change in the distribution of precipitation. We demonstrate using a nine-box model of the climate system that the phase relation between atmospheric $\mathrm{CO}_{2}$ and temperature can be opposite during different seasons and, moreover, that the phase relation can change during different stages of the glacial cycle. Ice-core records may thus favor one phase relation during certain stages over another. Our model can explain the observed lag of several thousand years of atmospheric $\mathrm{CO}_{2}$ behind temperature upon entering a stadial, given reasonable assumptions about the precipitation-weighted temperature record at Vostok.
\end{abstract}

\section{Introduction}

In order to understand the mechanism behind glacialinterglacial cycles, it is necessary to have information on the relative timing of events over the duration of such a cycle [Ghil and Childress, 1987; Imbrie et al., 1992, 1993; Ghil, 1994]. Ice cores provide a long time record of proxies for different climate variables, and several previous studies have tried to determine the relative phasing between different climate variables. Atmospheric $\mathrm{CO}_{2}$ and atmospheric temperature [Sowers and Bender, 1995; Fischer et al., 1999] or atmospheric $\mathrm{CO}_{2}$ and ice volume [Broecker and Henderson, 1998] were studied by comparing proxies in the same core, while correlations between Antarctic and Greenland ice cores were used in order to determine which hemisphere leads [Bender et al., 1994; Steig et al., 1998; Blunier and Brook, 2001].

In these studies, the isotopic records of the ice are translated into temperature. It is commonly assumed that the latter represents annual mean temperature [Jouzel et al., 1987; Bender et al., 1994; Broecker and Henderson, 1998; Petit et al., 1999]. Indeed, for today's climate, there is a good correlation between the annual mean local temperature and the isotopic temperature of precipitation both at Vostok [Jouzel et al., 1987; Jouzel et al., 1997] and in Greenland [Johnsen et al., 1995]. 
During the last few years, however, general circulation model (GCM) results [Krinner et al., 1997; Werner et al., 2000], as well as temperature estimates derived from boreholes [Johnsen et al., 1995; Cuffey et al., 1995], showed that the isotopic temperature in Greenland is significantly biased toward summer during stadials, mainly because of seasonal changes in precipitation [Krinner et al., 1997; Werner et al., 2000]. Delaygue et al. [2000a] and Krinner et al. [1997] argue that the treatment of the isotopic temperature record in the Vostok ice core as a proxy for annual mean temperature is still justified but uncertainties remain [Hendricks et al., 2000]. Temperature reconstruction from boreholes [Salamatin et al., 1998] suggests a glacialinterglacial temperature change that is $30 \%$ stronger than that derived from the isotope record. Lack of observations [Genthon et al., 1998] as well as published GCM studies that usually do not simulate correctly the precipitation conditions near Vostok [Jouzel et al., 1994; Werner et al., 2000; Delaygue et al., 2000b], prevent us from settling this issue with certainty.

Previous studies based on atmospheric GCM experiments examined the influence of precipitation seasonality on the interpretation of glacial-to-interglacial temperature differences [Jouzel et al., 1997; Krinner et al., 1997; Werner et al., 2000]. Since GCMs are so computerintensive, they have been used only to simulate modern and ice age climate as equilibrium responses to prescribed glacial conditions and orbital parameters. Unlike investigating the effect of seasonality on the amplitude of glacial-interglacial variations, the effect of seasonality on the phase relations between climate variables such as temperature and $\mathrm{CO}_{2}$ was therefore ignored.

\section{Model description}

Dealing with these phase relations during glacialinterglacial cycles clearly requires a physical model of the cycles that is sufficiently detailed. Gildor and Tziperman's [2000, 2001a,b] physical climate model includes simplified yet explicit model components for the oceanic overturning circulation, sea ice, land glaciers, atmosphere, and the carbon cycle. This model captures, in particular, a new mechanism for the 100-kyr oscillations that dominate the Late Pleistocene. The mechanism relies heavily on the radiative and insulating role of sea ice.

In the present paper we incorporate in the Gildor and Tziperman [2001b] model, which has three atmospheric and six oceanic boxes and which includes biogeochemical processes, the effect of insolation variations

[cf. Gildor and Tziperman, 2000]. This allows us to investigate the phase relationship between atmospheric $\mathrm{CO}_{2}$ concentrations and Southern Hemisphere temperatures on the paleoclimatic time scales. We demonstrate that this phase relation can be of opposite sign for different months (and seasons) during different stages of 
the glacial cycle, while annual mean temperature and $\mathrm{CO}_{2}$ are in phase.

An uncertainty of about 1 kyr persists in the age of $\mathrm{CO}_{2}$ relative to the ice [Fischer et al., 1999]. In spite of it, the Vostok records show that temperature and $\mathrm{CO}_{2}$ concentrations rise fairly synchronously during deglaciations, while $\mathrm{CO}_{2}$ decrease during glaciations lags the temperature decrease by several kyr [Petit et al., 1999]. This lag is especially pronounced at the end of interglacials 5.5 and 7.5 (see Figure 3 of Petit et al. [1999]). Our model provides a tentative explanation for the observed lead of Southern Hemisphere atmospheric temperature during early glaciation. The explanation assumes that the Vostok isotopic temperature is biased toward the late spring and early summer temperatures, as suggested by the studies reviewed above. These studies suggest that the relative contribution of the November-December-January precipitation to the total annual precipitation during glacial periods might be larger than at present (see Figure 2 of $D e$ laygue et al. [2000a]).

\section{Model results}

Figure 1 shows the results for temperatures and atmospheric $\mathrm{CO}_{2}$ concentrations in the southern atmospheric box of a 300-kyr simulation. Records for model $\mathrm{CO}_{2}$ and temperature taken for the month of November each year (upper panel) clearly show that $\mathrm{CO}_{2}$ lags southern temperature by a few kyr at the beginning of glaciation. In contrast, during deglaciation both atmospheric temperature and $\mathrm{CO}_{2}$ rise almost in phase. When both records represent the annual mean (lower panel), no phase difference arises in either glacial-cycle stage. This example demonstrates the care required when trying to correlate time series of different proxies, in order to identify lead-lag relations.

\section{Seasonal dependence of the $\mathrm{CO}_{2}$-vs.-temperature phase lag}

Different processes control the atmospheric temperature and atmospheric $\mathrm{CO}_{2}$ in high southern latitudes. In our model, the $100-\mathrm{kyr}$ variations in atmospheric $\mathrm{CO}_{2}$ are the result of changes in the rate of vertical mixing and in sea-ice cover in the Southern Hemisphere [Gildor and Tziperman, 2001b]. The $\mathrm{CO}_{2}$ variations superimposed on the 100-kyr cycle are dominated by solubility variations in high northern latitudes, where the surface ocean water absorbs $\mathrm{CO}_{2}$ from the atmosphere before sinking into the deep ocean.

Figure 2 shows that $\mathrm{CO}_{2}$ varies in phase with the average oceanic temperature, both in the annual mean and in November-only values. $\mathrm{CO}_{2}$ solubility is affected by ocean temperature, while both oceanic and atmospheric temperatures in and above the northern subpolar ocean are largely affected by albedo, and hence by the extent of the northern ice sheet [Gildor and Tziper-

Figure 1

Figure 2 
man, 2000]. The variations in the northern surface temperature are then carried by the thermohaline circulation and affect the deep-ocean temperature. Hence, atmospheric $\mathrm{CO}_{2}$ is highly correlated with boreal summer insolation in northern latitudes.

The model's southern polar atmospheric temperature is controlled by two main factors: sea-ice extent, via its albedo effect, and solar insolation. There is a high (inverse) correlation between sea-ice extent and atmospheric temperature, which is due to the high albedo of sea ice. This relation is observed throughout the year. However, while sea-ice extent is partially affected by the temperature of the deep ocean and hence by Northern Hemisphere processes [Gildor and Tziperman, 2001b], it is also modified by local insolation variations [Kim et al., 1998]. Thus the model's southern polar atmospheric temperature is affected by local insolation both directly and through the insolation effect on sea ice, but it is also affected by northern hemisphere condition.

Figure $2 \mathrm{~b}$ presents the relation between local insolation and atmospheric temperature in high southern latitudes during November, May, and for the annual mean. It is clear that insolation has a larger effect on atmospheric temperature during November, when the amount of insolation becomes significant. Hence, the relative contributions of local insolation and sea ice to southern atmospheric temperature differ from season to season, and change during the glacial cycle (see lower panel of Figure 2b). The dependence on the march of seasons is quite similar, albeit slightly less striking, when taking three-month seasons (NDJ and MJJ) into account (not shown), rather than single months (as in Fig. 1 and Fig. 2b).

\section{Discussion}

Climate information from marine sediments [Imbrie et al., 1992, 1993] and ice cores [Broecker and Henderson, 1998; Fischer et al., 1999; Steig et al., 1998] has been used by several previous studies to determine the sequence of events during past glaciation cycles in order to identify the mechanisms behind these cycles. A few recent studies have investigated the effect of seasonal change in polar precipitation on the reliability of glacial-interglacial temperature variations inferred from isotopic records [Steig et al., 1994; Jouzel et al., 1997; Krinner et al., 1997; Werner et al., 2000].

We have used here a simple, zonally averaged model to demonstrate that the phase relations between climate variables extracted from ice cores can differ from season to season and can change during the glacial cycle. Changes in the seasonal distribution of polar precipitation during a glacial cycle can therefore also affect our interpretation of lead-lag relations between different climate proxies extracted from ice cores. The reason for the seasonal dependence of the phase relations is that different processes affect the temporal behavior of each climate variable during a glaciation cycle. Some of these 
processes have a season-sensitive behavior.

A distinctive feature of the Vostok ice core [Petit et al., 1999] is the lag between atmospheric $\mathrm{CO}_{2}$ and local atmospheric temperature, particularly pronounced during early glaciation and vanishes during deglaciation. In our model, the shorter-period $\mathrm{CO}_{2}$ variations superimposed on the 100-kyr cycle are highly correlated with boreal summer insolation in northern latitudes. In contrast, high-latitude southern temperature is affected by both local insolation variation - which is out of phase with northern insolation for the dominant precessional variations - and by sea-ice albedo. The phase difference between $\mathrm{CO}_{2}$ and southern temperature varies therefore during the seasonal cycle, and can be different from one stage of a glaciation cycle to another. In our model, during early glaciation and for austral late spring and early summer, local temperature decrease leads atmospheric $\mathrm{CO}_{2}$. The opposite is the case, i.e. temperature decrease lags atmospheric $\mathrm{CO}_{2}$, during late fall and early winter.

It is quite plausible that the Vostok isotopic record during cold periods is biased toward austral spring and summer temperatures, as the Greenland record seems biased toward boreal summer, even though the bias might be somewhat smaller [Krinner et al., 1997; Delaygue et al., 2000a]. If so, the observed variable phase lag between atmospheric $\mathrm{CO}_{2}$ and temperature in the Vostok record can be explained by the seasonal bias of the phase relations (see Figure 1).

The model used here is highly idealized and our explanation for the observed phase difference between southern atmospheric temperature and atmospheric $\mathrm{CO}_{2}$ is admittedly speculative. Alternative possibilities include the existence of a nonlinear oscillatory mechanism that involves $\mathrm{CO}_{2}$ and various climate variables [Ghil, 1994; Saltzman and Verbitsky, 1994; Dettinger and Ghil, 1998] and isotopic temperature biases due to climate variations in the precipitation's source region [Cuffey and Vimeux, 2001]. Nonlinear oscillations can also account for changes in phase relations among variables during a glaciation cycle [Le Treut et al., 1988; Ghil, 1994].

Isotopic modeling studies using atmospheric GCMs have significantly improved during the past few years in simulating and explaining the observed record in Greenland. With a similar advance in their ability to simulate the Antarctic climate [Krinner and Genthon, 1998], GCMs could provide better estimates of the seasonal distribution of precipitation in Antarctica during different stages of a glaciation cycle. This should lead to a better understanding of lead-lag relations between climate variables in the Vostok ice core data and support or invalidate the present results.

Acknowledgments. It is a pleasure to thank Eli Tziperman for numerous discussions on the topic of this paper. This work is partially supported by the Israeli-US Binational Science Foundation and by the NOAA Postdoctoral 
Program in Climate and Global Change, administered by the University Corporation for Atmospheric Research (HG) and NSF grant ATM00-82131 (MG).

\section{References}

Bender, M., T. Sowers, M.L. Dickson, J. Orchards, P. Grootes, P.A. Mayewski, and M. A. Meese, Climate correlations between Greenland and Antarctica during the past 100,000 years, Nature, 372, 663-666, 1994.

Blunier, T., and E. Brook, Timing of millennial-scale climate change in Antarctica and Greenland during the last glacial period, Science, 291, 109-112, 2001.

Broecker, W., and G. Henderson, The sequence of events surrounding Termination II and their implication for the cause of glacial-interglacial $\mathrm{CO}_{2}$ changes, Paleoceanography, 13, 352-364, 1998.

Cuffey, K.M., and F. Vimeux, Covariation of carbon dioxide and temperature from the Vostok ice core after deuteriumexcess correction, Nature, 412, 523-527, 2001.

Cuffey, K., G. Clow, R. Alley, M. Stuiver, E. Waddington, and R. Saltus, Large Arctic temperature change at the Wisconsin-Holocene glacial transition, Science, 270, 455458, 1995.

Delaygue, G., J. Jouzel, V. Masson, R.D. Koster, and E. Bard, Validity of isotopic thermometer in central Antarctica: limited impact of glacial precipitation seasonality and moisture origin, Geophys. Res. Lett., 27, 2677-2680, 2000a.

Delaygue, G., V. Masson, J. Jouzel, and R.D. Koster, The origin of Antarctic precipitation: a modelling approach, Tellus, 52B, 19-36, 2000b.

Dettinger, M.D., and M. Ghil, Seasonal and interannual variations of atmospheric $\mathrm{CO}_{2}$ and climate, Tellus, 50B, $1-24,1998$.

Fischer, H., M. Wahlen, J. Smith, D. Mastroianni, and B. Deck, Ice core records of atmospheric $\mathrm{CO}_{2}$ around the last three glacial terminations, Science, 283, 712-714, 1999.

Genthon, C., G. Krinner, and M. Déqué, Intra-annual variability of Antarctic precipitation from weather forecasts and high-resolution climate models, Annals Glaciol., 27, 488-494, 1998.

Ghil, M., Cryothermodynamics: the chaotic dynamics of paleoclimate, Physica D, 77, 130-159, 1994.

Ghil, M., and S. Childress, Topics in Geophysical Fluid Dynamics: Atmospheric Dynamics, Dynamo Theory and Climate Dynamics, Springer-Verlag, New York, 1987.

Gildor, H., and E. Tziperman, A sea-ice climate-switch mechanism for the $100 \mathrm{kyr}$ glacial cycles, J. Geophys. Res., 106, 9117-9133, 2001a.

Gildor, H., and E. Tziperman, Physical mechanisms behind biogeochemical glacial-interglacial $\mathrm{CO}_{2}$ variations, Geophys. Res. Lett., 28, 2421-2424, 2001b.

Gildor, H., and E. Tziperman, Sea ice as the glacial cycles climate switch: Role of seasonal and Milankovitch solar forcing, Paleoceanography, 15, 605-615, 2000.

Hendricks, M.B., D.J. DePaolo, and R.C. Cohen, Space and time variation of $\delta^{18} O$ and $\delta D$ in precipitation: Can paleotemperature be estimated from ice cores?, Global Biogeochem. Cycles, 14, 851-861, 2000.

Imbrie, J., et al., On the structure and origin of major glaciation cycles. 1. Linear responses to Milankovitch forcing, Paleoceanography, 7, 701-738, 1992

Imbrie, J., et al., On the structure and origin of major glaciation cycles 2. The 100,000-year cycle, Paleoceanography, 8, 699-735, 1993.

Johnsen, S.J., D. Dahl-Jensen, W. Dansgaard, and N. Gundestrup, Greenland paleotemperatures derived from 
GRIP bore hole temperature and ice core isotope profiles, Tellus, 47B, 624-629, 1995.

Jouzel, J., et al., Validity of the temperature reconstruction from water isotopes in cores, J. Geophys. Res., 102, 26471-26487, 1997.

Jouzel, J., R.D. Koster, R.J. Suozzo, and G.L. Russell, Stable water isotope behavior during the last glacial maximum: A general circulation model analysis, J. Geophys. Res., 99, 25791-25801, 1994.

Jouzel, J., C. Lorius, J.R. Petit, C. Genthon, N.I. Barkov, V.M. Kotlyakov, and V.M. Petrov, Vostok ice core: a continous isotope temperature record over the last climatic cycle (160,000 years), Nature, 329, 403-407, 1987.

Kim, S.J., T. Crowley, and A. Stössel, Local orbital forcing of Antarctic climate change during the last interglacial, Science, 280, 728-730, 1998.

Krinner, G., C. Genthon, and J. Jouzel, GCM analysis of local influence on ice core $\delta$ signals, Geophys. Res. Lett., 24, 2825-2828, 1997.

Krinner, G., and C. Genthon, GCM simulations of the Last Glacial Maximum surface climate of Greenland and Antarctica, Clim. Dyn., 14, 741-758, 1998.

Le Treut, H., J. Portes, J. Jouzel, and M. Ghil, Isotopic modeling of climatic oscillations-implications for a comparative-study of marine and ice core records, J. Geophys. Res., 93, 9365-9383, 1988.

Petit, J.R., et al., Climate and atmospheric history of the past 420,000 years from the Vostok ice core, Antarctica, Nature, 399, 429-436, 1999.

Salamatin, A., V. Lipenkov, N. Barkov, J. Jouzel, J. Petit, and D. Raynaud, Ice core age dating and paleothermometer calibration based on isotope and temperature profiles from deep boreholes at Vostok Station (East Antarctica), J. Geophys. Res., 103, 8963-8977, 1998.

Saltzman, B., and M. Verbitsky, $\mathrm{CO}_{2}$ and glacial cycles, Nature, 367, 419, 1994.

Sowers, T., and M. Bender, Climate records covering the last deglaciation, Science, 269, 210-214, 1995.

Steig, E., P. Grootes, and M. Stuiver, Seasonal precipitation timing and ice core records, Science, 266, 1885-1886, 1994.

Steig, E.J., E.J. Brook, J.W.C. White, C.M. Sucher, M.L. Bender, S.J. Lehman, D.L. Morse, E.D. Waddington, and G.D. Clow, Synchronous climate changes in Antarctica and the North Atlantic, Science, 282, 92-95, 1998.

Werner, M., U. Mikolajewicz, M. Heimann, and G. Hoffman, Borehole versus isotope temperature on Greenland: Seasonality does matter, Geophys. Res. Lett., 27, 723-726, 2000.

H. Gildor, Department of Environmental Sciences,

Weizmann Institute of Science, Rehovot, 76100, Israel. (email: hezi.gildor@weizmann.ac.il).

M. Ghil, Department of Atmospheric Sciences and Institute of Geophysics and Planetary Physics, UCLA, Los Angeles, CA 90095-1565. (e-mail: ghil@atmos.ucla.edu)

(Received

${ }^{1}$ Now at Lamont-Doherty Earth Observatory of Columbia University, Palisades, New York. 
Figure 1. Seasonal effects on phase relations: atmospheric $\mathrm{CO}_{2}$ (light solid, right axes, in ppm) and temperature (heavy, left axes, in ${ }^{\circ} \mathrm{C}$ ) in the southernmost of the three atmospheric boxes. Upper panel: consecutive Novembers and lower panel: annual means.

Figure 1. Seasonal effects on phase relations: atmospheric $\mathrm{CO}_{2}$ (light solid, right axes, in ppm) and temperature (heavy, left axes, in ${ }^{\circ} \mathrm{C}$ ) in the southernmost of the three atmospheric boxes. Upper panel: consecutive Novembers and lower panel: annual means.

Figure 2. Factors that control the phase relationships. a) Evolution of atmospheric $\mathrm{CO}_{2}$ (light solid, right axes, in ppm) and oceanic average temperature (heavy, left axes, in ${ }^{\circ} \mathrm{C}$ ) for consecutive Novembers (upper panel) and annual means (lower panel). b) Evolution of southern-box atmospheric temperature (heavy, left axes, in ${ }^{\circ} \mathrm{C}$ ) and insolation (light solid, right axes, in $\mathrm{Wm}^{-2}$ ): (upper panel) for consecutive Novembers; (middle panel) for consecutive months of May; and (lower panel) for the annual mean.

Figure 2. Factors that control the phase relationships. a) Evolution of atmospheric $\mathrm{CO}_{2}$ (light solid, right axes, in $\mathrm{ppm}$ ) and oceanic average temperature (heavy, left axes, in ${ }^{\circ} \mathrm{C}$ ) for consecutive Novembers (upper panel) and annual means (lower panel). b) Evolution of southern-box atmospheric temperature (heavy, left axes, in ${ }^{\circ} \mathrm{C}$ ) and insolation (light solid, right axes, in $\mathrm{Wm}^{-2}$ ): (upper panel) for consecutive Novembers; (middle panel) for consecutive months of May; and (lower panel) for the annual mean.

GILDOR AND GHIL: PHASE RELATIONS IN ICE-CORE RECORDS

GILDOR AND GHIL: PHASE RELATIONS IN ICE-CORE RECORDS

GILDOR AND GHIL: PHASE RELATIONS IN ICE-CORE RECORDS

GILDOR AND GHIL: PHASE RELATIONS IN ICE-CORE RECORDS

GILDOR AND GHIL: PHASE RELATIONS IN ICE-CORE RECORDS

GILDOR AND GHIL: PHASE RELATIONS IN ICE-CORE RECORDS

GILDOR AND GHIL: PHASE RELATIONS IN ICE-CORE RECORDS

GILDOR AND GHIL: PHASE RELATIONS IN ICE-CORE RECORDS

GILDOR AND GHIL: PHASE RELATIONS IN ICE-CORE RECORDS

GILDOR AND GHIL: PHASE RELATIONS IN ICE-CORE RECORDS

GILDOR AND GHIL: PHASE RELATIONS IN ICE-CORE RECORDS

GILDOR AND GHIL: PHASE RELATIONS IN ICE-CORE RECORDS

GILDOR AND GHIL: PHASE RELATIONS IN ICE-CORE RECORDS

GILDOR AND GHIL: PHASE RELATIONS IN ICE-CORE RECORDS

GILDOR AND GHIL: PHASE RELATIONS IN ICE-CORE RECORDS

GILDOR AND GHIL: PHASE RELATIONS IN ICE-CORE RECORDS 